\title{
Proteasome inhibition by MG132 induces growth inhibition and death of human pulmonary fibroblast cells in a caspase-independent manner
}

\author{
BO RA YOU and WOO HYUN PARK \\ Department of Physiology, Medical School, Institute for Medical Sciences, \\ Chonbuk National University, JeonJu 561-180, Republic of Korea
}

Received November 26, 2010; Accepted January 17, 2011

DOI: $10.3892 /$ or.2011.1211

\begin{abstract}
MG132 as a proteasome inhibitor that can induce apoptotic cell death in various cell types including lung cancer cells. We investigated the cellular effects of MG132 on human pulmonary fibroblast (HPF) cells in relation to cell growth inhibition and death, and described the molecular mechanisms of MG132 in HPF cell death. This agent dose-dependently inhibited the growth of $\mathrm{HPF}$ cells with an $\mathrm{IC}_{50}$ of approximately $20 \mu \mathrm{M}$ at $24 \mathrm{~h}$ and induced cell death accompanied by the loss of mitochondrial membrane potential (MMP; $\Delta \Psi_{\mathrm{m}}$ ) and an increase in caspase- 3 and -8 activities. MG132 increased intracellular ROS levels and GSH-depleted cell numbers. However, all the tested caspase inhibitors intensified HPF growth inhibition by MG132 and caspase- 9 inhibitor also enhanced cell death and MMP $\left(\Delta \Psi_{\mathrm{m}}\right)$ loss. Moreover, the administration of Bcl-2 siRNA augmented HPF cell death by MG132 whereas p53, Bax, caspase-3 and -8 siRNAs did not strongly affect cell death. In addition, each caspase inhibitor and siRNA differently affects ROS levels including $\mathrm{O}_{2}{ }^{-}$- regardless of cell growth inhibition and cell death levels. Caspase- 8 and -9 inhibitors
\end{abstract}

Correspondence to: Dr Woo Hyun Park, Department of Physiology, Medical School, Chonbuk National University, Institute for Medical Sciences, JeonJu 561-180, Republic of Korea

E-mail: parkwh71@chonbuk.ac.kr

Abbreviations: HPF, human pulmonary fibroblast; MG132, carbobenzoxy-Leu-Leu-leucinal; ROS, reactive oxygen species; MMP $\left(\Delta \Psi_{\mathrm{m}}\right)$, mitochondrial membrane potential; Z-VAD-FMK, benzyloxycarbonyl-Val-Ala-Asp-fluoromethylketone; Z-DEVD-FMK, benzyloxycarbonyl-Asp-Glu-Val-Asp-fluoromethylketone; Z-IETDFMK, benzyloxycarbonyl-Ile-Glu-Thr-Asp-fluoromethylketone; Z-LEHD-FMK, benzyloxycarbonyl-Leu-Glu-His-Asp-fluoromethylketone; FBS, fetal bovine serum; PI, propidium iodide; FITC, fluorescein isothiocyanate; $\mathrm{H}_{2}$ DCFDA, 2',7'-dichlorodihydrofluorescein diacetate; DHE, dihydroethidium; GSH, glutathione; CMFDA, 5-chloromethylfluorescein diacetate; MTT, 3-(4,5-dimethylthiazol2-yl)-2,5-diphenyltetrazolium bromide; siRNA, small interfering RNA

Key words: MG132, proteasome, cell death, human pulmonary fibroblast, reactive oxygen species increased the number of GSH-depleted cells in MG132-treated HPF cells. In conclusion, MG132 induced growth inhibition and death in HPF cells in a caspase-independent manner. The growth inhibition and death of HPF cells by MG132 and/or each caspase inhibitor or apoptosis-related siRNA were not tightly related to the changes in ROS levels.

\section{Introduction}

The ubiquitin-dependent proteasomal system presents the foremost non-lysosomal corridor $(1,2)$. The proteasome consists of large multi-subunit protease complexes; a $20 \mathrm{~S}$ catalytic and two $19 \mathrm{~S}$ regulatory subunits. The protease activity works in a channel at the center of the 20S subunit and exhibits 3 distinguishable enzymatic activities: chymotrypsin-like, trypsin-like and caspase-like (3). Many proteins despoiled by proteasome are implicated in crucial processes: for example, cell cycle-regulatory proteins (cyclins A, B, D and E; p21 and p27) and apoptotic-related proteins (p53 and Bcl-2) (4). Transformed cells including cancer cells accumulate more misfolded/mutated/damaged proteins due to the elevated duplication rate of malignant cells, which are disposed of by the proteasome (4). Thus, these cells can be much more vulnerable to proteasome inhibition than normal cells. Apoptosis in cancer cells is closely connected with the activity of ubiquitin/proteasome pathways $(5,6)$. Accordingly, the inhibition of proteasome function has emerged as a useful strategy to maneuver apoptosis.

The peptide aldehyde MG132 (carbobenzoxy-Leu-Leuleucinal) efficiently prevents the proteolytic activity of the proteasome complex (7). Various proteasome inhibitors including MG132 have been demonstrated to stimulate apoptotic cell death through the induction of reactive oxygen species (ROS) $(8,9)$. ROS formation and glutathione (GSH; a major non-protein antioxidant in the cell) depletion by proteasome inhibitors may trigger mitochondrial dysfunction and subsequent cytochrome c release, which can lead to cell death $(10,11)$. The mechanism underlying ROS generation after inhibition of the proteasome is still imprecise. In addition, although cells have antioxidant systems to manage their redox state, excessive production of ROS can be induced by endogenous and/or exogenous sources, which then initiates 
events that lead to cell death or survival, depending on cell types (12-14).

Lung cancer is a main cause of cancer death in developed countries. Since the clinical use of conventional drugs is limited due to intrinsic or acquired resistance and toxicity, various novel remedial strategies are presently under consideration (15). Studies of the molecular mechanisms of cytotoxic drug action have shed light on the treatment of lung cancer. Novel drugs that aim at specific intracellular pathways related to the distinctive properties of cancer cells continue to be developed. It has been reported that proteasome inhibitor bortezomib (PS-341, Velcade) inhibits lung cancer cells $(16,17)$. However, the role of MG132 in lung cancer cells is not fully understood. We recently demonstrated that MG132 reduced the growth of Calu-6 and A549 lung cancer cells via apoptosis and GSH depletion $(18,19)$. On the other hand, little is known about the cellular effects of MG132 on normal primary lung cells in relation to cell death.

Because cancer cells accumulate more misfolded/mutated/ damaged proteins which are disposed of by the proteasome (4), it is worthy to know the susceptibility of normal primary lung cells to MG132 and to understand its toxicological mechanisms in these cells. We assumed that the susceptibility of normal human pulmonary fibroblast (HPF) cells to MG132 is lower than that of lung cancer cells. In the present study, we investigated the cellular effects of MG132 on HPF cells in relation to cell growth inhibition and death, and describe the molecular mechanisms of MG132 in HPF cell death. In addition we examined the effects of MG132 and/or caspase inhibitors or apoptosis-related siRNAs on ROS and GSH in HPF cells.

\section{Materials and methods}

Cell culture. The human pulmonary fibroblast (HPF) cells from PromoCell $\mathrm{GmbH}$ (Heidelberg, Germany) were maintained in humidified incubator containing $5 \% \mathrm{CO}_{2}$ at $37^{\circ} \mathrm{C}$. HPF cells were cultured in RPMI-1640 supplemented with $10 \%$ fetal bovine serum (FBS) and $1 \%$ penicillin-streptomycin (Gibco-BRL, Grand Island, NY). HPF cells were used between passages 4 and 8 .

Reagents. MG132 was purchased from Calbiochem (San Diego, CA) and was dissolved in dimethyl sulfoxide (DMSO; Sigma-Aldrich, St. Louis, MO) solution buffer. The pancaspase inhibitor (Z-VAD-FMK; benzyloxycarbonyl-Val-AlaAsp-fluoromethylketone), caspase-3 inhibitor (Z-DEVD-FMK; benzyloxycarbonyl-Asp-Glu-Val-Asp-fluoromethylketone), caspase-8 inhibitor (Z-IETD-FMK; benzyloxycarbonyl-IleGlu-Thr-Asp-fluoromethylketone) and caspase-9 inhibitor (Z-LEHD-FMK; benzyloxycarbonyl-Leu-Glu-His-Aspfluoromethylketone) were obtained from R\&D Systems, Inc. (Minneapolis, MN) and were dissolved in DMSO. Based on a previous study (20), cells were pretreated with or without each caspase inhibitor for $1 \mathrm{~h}$ prior to MG132 treatment. DMSO $(0.2 \%)$ was used as a control vehicle and it did not appear to affect cell growth or death.

Cell growth inhibition assays. Cell numbers in HPF cells treated with MG132 and/or each caspase inhibitor were determined by trypan blue cell counting, and cell growth inhibition in these cells was indirectly evaluated by measuring 3-(4,5-dimethylthiazol-2-yl)-2,5-diphenyltetrazolium bromide (MTT) dye absorbance as previously described $(21,22)$. In brief, $2 \times 10^{5}$ cells per well were seeded in 24 -well plates (Nunc, Roskilde, Denmark) for cell counting and $5 \times 10^{3}$ cells per well were seeded in 96-well microtiter plates (Nunc) for MTT assays. After exposure to the indicated amounts (0.1-30 $\mu \mathrm{M})$ of MG132 with or without $15 \mu \mathrm{M}$ of a given caspase inhibitor for $24 \mathrm{~h}$, the cells in the 24-well plates were collected with trypsin digestion for trypan blue cell counting and the cells in the 96-well plates were used for MTT assays. Twenty microliters of MTT solution [2 $\mathrm{mg} / \mathrm{ml}$ in phosphate-buffered saline (PBS)] was added to each well of the 96-well plates. The plates were incubated for additional $4 \mathrm{~h}$ at $37^{\circ} \mathrm{C}$. Media in plates were withdrawn by pipetting and $200 \mu 1$ of DMSO was added to each well to solubilize the formazan crystals. Optical density was measured at $570 \mathrm{~nm}$ using a microplate reader (Spectra MAX 340, Molecular Devices Co., Sunnyvale, CA).

Western blot analysis. The patterns of ubiquitinated proteins were evaluated using Western blot analysis. In brief, $1 \times 10^{6}$ cells in $60-\mathrm{mm}$ culture dish (Nunc) were incubated with 10 or $30 \mu \mathrm{M}$ MG132 for $24 \mathrm{~h}$. The cells were then washed in PBS and suspended in 5 volumes of lysis buffer (20 mM HEPES, pH 7.9, $20 \%$ glycerol, $200 \mathrm{mM} \mathrm{KCl}, 0.5 \mathrm{mM}$ EDTA, $0.5 \%$ NP40, $0.5 \mathrm{mM}$ DTT, $1 \%$ protease inhibitor cocktail). Supernatant protein concentrations were determined using the Bradford method. Samples containing $40 \mu \mathrm{g}$ total protein were resolved by $12.5 \%$ SDS-PAGE gels, transferred to Immobilon-P PVDF membranes (Millipore, Billerica, MA) by electroblotting and then probed with anti-ubiquitin and anti- $\beta$-actin antibodies (Santa Cruz Biotechnology, Santa Cruz, CA). Membranes were incubated with horseradish peroxidase-conjugated secondary antibodies. Blots were developed using an ECL kit (Amersham, Arlington Heights, IL).

Cell cycle and sub-G1 analysis. Cell cycle and sub-G1 cells were determined by propidium iodide (PI, Sigma-Aldrich; $\mathrm{Ex} / \mathrm{Em}=488 \mathrm{~nm} / 617 \mathrm{~nm}$ ) staining, as previously described (23). In brief, $1 \times 10^{6}$ cells in $60-\mathrm{mm}$ culture dish (Nunc) were incubated with the indicated amounts $(0.1-30 \mu \mathrm{M})$ of MG132 for $24 \mathrm{~h}$. Cells were then washed with PBS and fixed in 70\% ethanol. Cells were washed again with PBS, then incubated with PI $(10 \mu \mathrm{g} / \mathrm{ml})$ with simultaneous RNase treatment at $37^{\circ} \mathrm{C}$ for $30 \mathrm{~min}$. Cellular DNA content was measured using a FACStar flow cytometer (Becton-Dickinson, Franklin Lakes, $\mathrm{NJ})$.

Annexin V/PI staining for cell death detection. Apoptosis was determined by staining cells with Annexin V-fluorescein isothiocyanate (FITC, PharMingen, San Diego, CA; Ex/Em = $488 \mathrm{~nm} / 519 \mathrm{~nm}$ ) and propidium iodide (PI; Sigma-Aldrich; Ex/ $\mathrm{Em}=488 \mathrm{~nm} / 617 \mathrm{~nm}$ ). In brief, $1 \times 10^{6}$ cells in $60-\mathrm{mm}$ culture dish (Nunc) were incubated with MG132 with or without a given caspase inhibitor or siRNA duplex for $24 \mathrm{~h}$. Cells were washed twice with cold PBS and then resuspended in $500 \mu 1$ of binding buffer (10 mM HEPES/ $\mathrm{NaOH} \mathrm{pH} 7.4,140 \mathrm{mM} \mathrm{NaCl}$, $2.5 \mathrm{mM} \mathrm{CaCl}_{2}$ ) at a concentration of $1 \times 10^{6}$ cells $/ \mathrm{ml}$. Five microliters of Annexin V-FITC and PI $(1 \mu \mathrm{g} / \mathrm{ml})$ were then 
added to these cells, which were analyzed with a FACStar flow cytometer (Becton-Dickinson). Viable cells were negative for both PI and Annexin V; apoptotic cells were positive for Annexin V and negative for PI, whereas late apoptotic dead cells displayed both high Annexin V and PI labeling. Non-viable cells, which underwent necrosis, were positive for PI and negative for Annexin V.

Measurement of $\operatorname{MMP}\left(\Delta \Psi_{m}\right) \cdot \operatorname{MMP}\left(\Delta \Psi_{\mathrm{m}}\right)$ levels were measured using a rhodamine 123 fluorescent dye (Sigma-Aldrich; Ex/ $\mathrm{Em}=485 \mathrm{~nm} / 535 \mathrm{~nm}$ ) as previously described (22). In brief, $1 \times 10^{6}$ cells in 60-mm culture dish (Nunc) were incubated with MG132 with or without $15 \mu \mathrm{M}$ of a given caspase inhibitor for $24 \mathrm{~h}$. Cells were washed twice with PBS and incubated with the rhodamine $123(0.1 \mu \mathrm{g} / \mathrm{ml})$ at $37^{\circ} \mathrm{C}$ for $30 \mathrm{~min}$. Rhodamine 123 staining intensity was determined by flow cytometry (BectonDickinson). An absence of rhodamine 123 from cells indicated the loss of MMP $\left(\Delta \Psi_{\mathrm{m}}\right)$ in HPF cells. The MMP $\left(\Delta \Psi_{\mathrm{m}}\right)$ levels in the cells, excluding MMP $\left(\Delta \Psi_{\mathrm{m}}\right)$ loss cells, were expressed as the mean fluorescence intensity (MFI), which was calculated by CellQuest software (Becton-Dickinson).

Quantification of caspase-3 and caspase- 8 activities. The activities of caspase- 3 and -8 were assessed using the caspase- 3 and -8 Colorimetric Assay Kits (R\&D Systems, Inc.). In brief, $1 \times 10^{6}$ cells in $60-\mathrm{mm}$ culture dish (Nunc) were incubated with $10 \mu \mathrm{M}$ MG132 for $24 \mathrm{~h}$. The cells were then washed in PBS and suspended in 5 volumes of lysis buffer [20 mM HEPES pH 7.9, $20 \%$ glycerol, $200 \mathrm{mM} \mathrm{KCl,} 0.5 \mathrm{mM}$ EDTA, 0.5\% NP40, $0.5 \mathrm{mM}$ DTT, $1 \%$ protease inhibitor cocktail (from Sigma)]. Supernatant samples containing $50 \mu \mathrm{g}$ of total protein were used for determination of caspase- 3 and -8 activities. These samples were added to each well in the 96-well microtiter plates (Nunc) with the DEVD-pNA for the caspase-3 activity assay or IETD-pNA for the caspase- 8 activity assay at $37^{\circ} \mathrm{C}$ for $1 \mathrm{~h}$. The optical density of each well was measured at $405 \mathrm{~nm}$ using a microplate reader (Spectra MAX 340, Molecular Devices Co.). The activities of caspase- 3 and -8 were expressed in arbitrary absorbance units.

Detection of intracellular $\mathrm{ROS}$ and $\mathrm{O}_{2} \cdot$ - levels. Intracellular ROS were detected by means of an oxidation-sensitive fluorescent probe dye, 2',7'-dichlorodihydrofluorescein diacetate $\left(\mathrm{H}_{2} \mathrm{DCFDA}\right.$, Invitrogen Molecular Probes, OR; Ex/Em = $495 \mathrm{~nm} / 529 \mathrm{~nm}$ ) (24). As $\mathrm{H}_{2}$ DCFDA is poorly selective for $\mathrm{O}_{2}{ }^{\circ-}$, dihydroethidium (DHE, Invitrogen Molecular Probes; $\mathrm{Ex} / \mathrm{Em}=518 \mathrm{~nm} / 605 \mathrm{~nm}$ ), which is highly selective for $\mathrm{O}_{2}{ }^{\circ}$, was used for its detection. In brief, $1 \times 10^{6}$ cells in $60-\mathrm{mm}$ culture dish (Nunc) were incubated with MG132 with or without a given caspase inhibitor or siRNA duplex for $24 \mathrm{~h}$. Cells were then washed in PBS and incubated with $20 \mu \mathrm{M}$ $\mathrm{H}_{2}$ DCFDA or DHE at $37^{\circ} \mathrm{C}$ for $30 \mathrm{~min}$. DCF and DHE fluorescence was detected using a FACStar flow cytometer (Becton-Dickinson). ROS and $\mathrm{O}_{2}{ }^{-}$levels were expressed as mean fluorescence intensity (MFI), which was calculated by CellQuest software (Becton-Dickinson).

Detection of the intracellular glutathione (GSH). Cellular GSH levels were analyzed using a 5-chloromethylfluorescein diacetate dye (CMFDA, Invitrogen Molecular Probes; Ex/
$\mathrm{Em}=522 \mathrm{~nm} / 595 \mathrm{~nm}$ ) as previously described (24). In brief, $1 \times 10^{6}$ cells in $60-\mathrm{mm}$ culture dish (Nunc) were incubated with MG132 with or without a given caspase inhibitor for $24 \mathrm{~h}$. Cells were then washed with PBS and incubated with $5 \mu \mathrm{M}$ CMFDA at $37^{\circ} \mathrm{C}$ for $30 \mathrm{~min}$. CMF fluorescence intensity was determined using a FACStar flow cytometer (BectonDickinson). Negative CMF staining (GSH depleted) cells were expressed as the percent of (-) CMF cells.

Transfection of cells with apoptosis-related siRNAs. Gene silencing of p53, Bax, Bcl-2, caspase-3 and caspase- 8 was performed as previously described (25). A non-specific control siRNA duplex [5'-CCUACGCCACCAAUUUCGU (dTdT)-3'], p53 siRNA duplex [5'-CACUACAACUACAUGU GUA(dTdT)-3'], Bax siRNA duplex [5'-GCUGGACAUUGGA CUUCCU(dTdT)-3'], Bcl-2 siRNA duplex [5'-CAGAAGUCU GGGAAUCGAU(dTdT)-3'], caspase-3 siRNA duplex [5'-AGU AUGCCGACAAGCUUGA(dTdT)-3'] and caspase-8 siRNA duplex [5'-GCUGCUCUUCCGAAUUAAU(dTdT)-3'] were purchased from the Bioneer Corp. (Daejeon, South Korea). In brief, $2.5 \times 10^{5}$ cells in 6-well plates (Nunc) were incubated in RPMI-1640 supplemented with $10 \%$ FBS. The next day, cells ( $\sim 30-40 \%$ confluence) in each well were transfected with the control or each siRNA duplex [80 pmol in Opti-MEM (Gibco-BRL)] using Lipofectamine 2000, according to the manufacturer's instructions (Invitrogen, Branford, CT). One day later, cells were treated with or without $30 \mu \mathrm{M}$ MG132 for additional $24 \mathrm{~h}$. The transfected cells were collected and used for the measurement of Annexin V-FITC/PI staining cells and ROS levels.

Statistical analysis. The results represent the mean of at least three independent experiments (mean \pm SD). The data were analyzed using Instat software (GraphPad Prism4, San Diego, CA). The Student's t-test or one-way analysis of variance (ANOVA) with post hoc analysis using Tukey's multiple comparison test was used for parametric data. Statistical significance was defined as $\mathrm{p}<0.05$.

\section{Results}

Effects of MG132 on cell growth in HPF cells. We examined the effect of MG132 on the growth of HPF cells at $24 \mathrm{~h}$. Based on an MTT assay, MG132 dose-dependently inhibited the growth of HPF cells with an $\mathrm{IC}_{50}$ of $\sim 20 \mu \mathrm{M}$ (Fig. 1A). In addition, treatment with $0.5-30 \mu \mathrm{M}$ MG132 significantly decreased the population of viable (trypan blue-negative) HPF cells in a dose-dependent manner whereas the numbers of dead (trypan blue-positive) cells dose-dependently increased in MG132-treated cells (Fig. 1B). The ratio of dead cells to viable cells was increased by MG132 treatment. When the cell cycle distributions in MG132-treated HPF cells were examined, $10 \mu \mathrm{M}$ MG132 significantly induced S and G2-M phase arrests of the cell cycle at $24 \mathrm{~h}$ compared with control cells (data not shown). Moreover, we observed that MG132 increased the level of anonymous ubiquitinated proteins in HPF cells compared with that of the control cells (Fig. 1C).

Effects of MG132 on apoptosis and MMP $\left(\Delta \Psi_{m}\right)$ in HPF cells. We determined whether MG132 induces cell death via apop- 

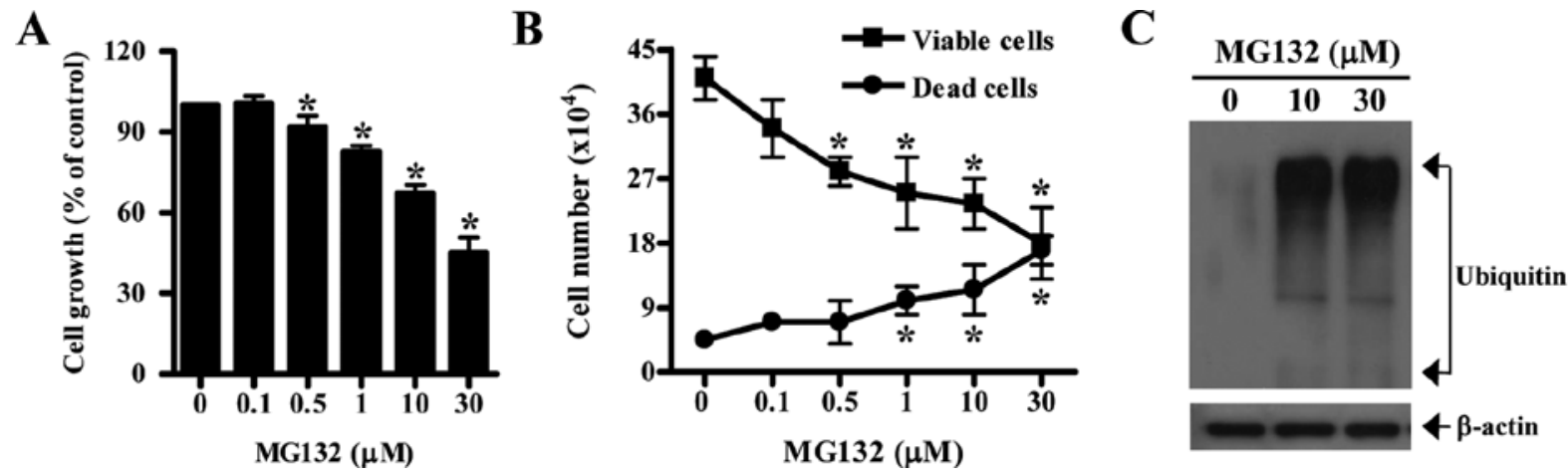

Figure 1. Effects of MG132 on cell growth in HPF cells. Exponentially growing cells were treated with the indicated amounts of MG132 for $24 \mathrm{~h}$. (A) The graph shows cellular growth changes in HPF cells, as assessed by MTT assays. (B) The graphs show the viable (trypan blue-negative) and dead (trypan blue-positive) cell numbers in HPF cells. (C) Samples ( $40 \mu \mathrm{g}$ ) of protein extracts were resolved by SDS-PAGE gel, transferred onto PVDF membranes and immunoblotted with the indicated antibodies against ubiquitin and $\beta$-actin. " $\mathrm{p}<0.05$ compared with the control group.

A

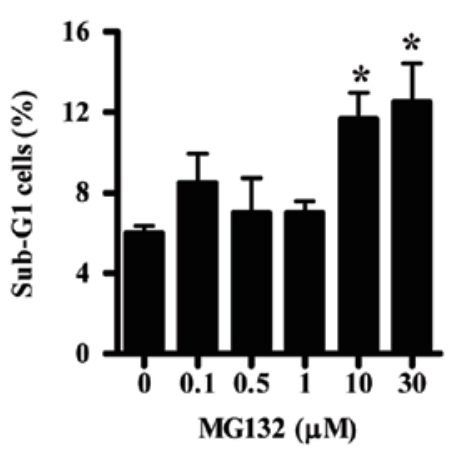

C

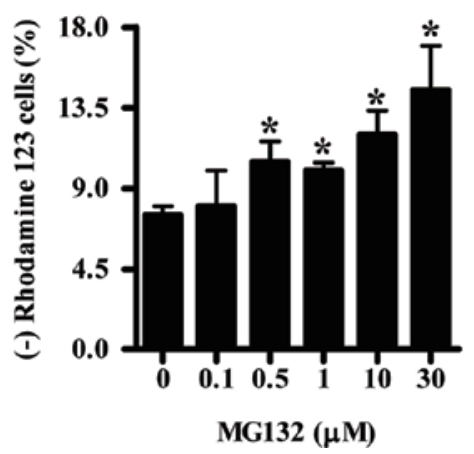

B

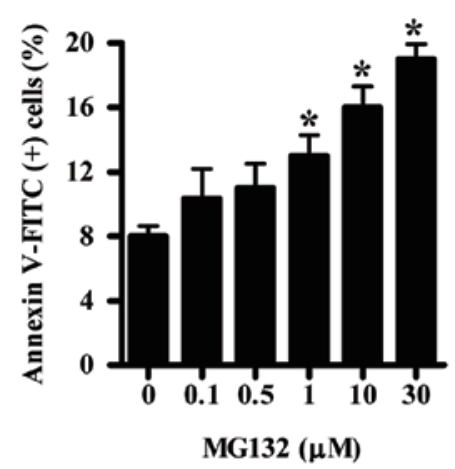

D

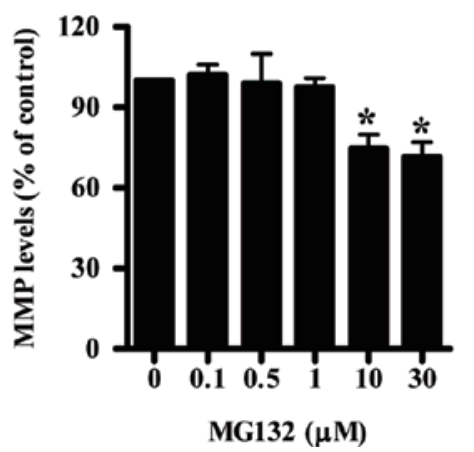

$\mathbf{E}$
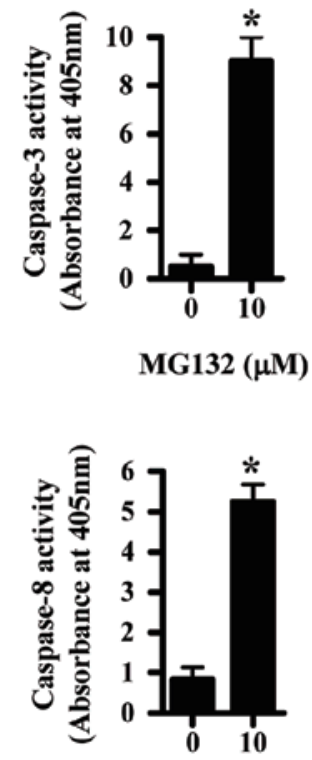

MG132 ( $\mu \mathrm{M})$

Figure 2. Effects of MG132 on cell death and MMP $\left(\Delta \Psi_{\mathrm{m}}\right)$ in HPF cells. Exponentially growing cells were treated with the indicated amounts of MG132 for $24 \mathrm{~h}$. (A and B) Sub-G1 cells (A) and Annexin V-FITC cells (B) were measured with a FACStar flow cytometer. (C and D) MMP ( $\left.\Delta \Psi_{\mathrm{m}}\right)$ was measured with a FACStar flow cytometer. Graphs show the percent of rhodamine 123-negative [MMP $\left(\Delta \Psi_{\mathrm{m}}\right)$ loss] cells $(\mathrm{C})$ and MMP $\left(\Delta \Psi_{\mathrm{m}}\right)$ levels in the cells, excluding MMP $\left(\Delta \Psi_{\mathrm{m}}\right)$ loss cells (D). (E) The graphs show the activities of caspase-3 and caspase-8 in HPF cells treated with or without $10 \mu \mathrm{M}$ MG132. "p $<0.05$ compared with the control group.

tosis in HPF cells. As shown in Fig. 2A, MG132 increased the number of sub-G1 cells at $24 \mathrm{~h}$. When HPF cells were stained with Annexin V-FITC, the proportion of Annexin V-stained cells following MG132 treatment was significantly increased in a dose-dependent manner (Fig. 2B). In addition, when the loss of MMP $\left(\Delta \Psi_{\mathrm{m}}\right)$ in MG132-treated HPF cells was determined using a rhodamine 123 dye, MG132 induced the loss of MMP $\left(\Delta \Psi_{\mathrm{m}}\right)$ in HPF cells in a dose-dependent manner (Fig. 2C). Treatment with 10 or $30 \mu \mathrm{M}$ MG132 reduced MMP $\left(\Delta \Psi_{\mathrm{m}}\right)$ level in the cells excluding MMP $\left(\Delta \Psi_{\mathrm{m}}\right)$ loss cells (Fig. 2D). Caspase-3 plays an essential role as an executioner in apoptosis
(26). As shown in Fig. 2E, MG132 increased caspase-3 activity in HPF cells. We also observed the disappearance of procaspase-3 protein in MG132-treated HPF cells (data not shown). Furthermore, the activity of caspase- 8 , which is known to be involved in receptor- or extrinsic-mediated apoptosis (27), was increased in MG132-treated HPF cells (Fig. 2E).

Effects of caspase inhibitors on cell growth, apoptosis and MMP $\left(\Delta \Psi_{m}\right)$ in MG132-treated HPF cells. Next, we investigated the effects of caspase inhibitors on the growth and death of MG132-treated HPF cells. For this experiment, $10 \mu \mathrm{M}$ 
$\mathbf{A}$

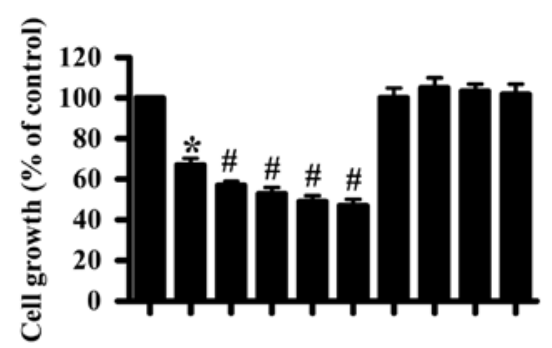

B

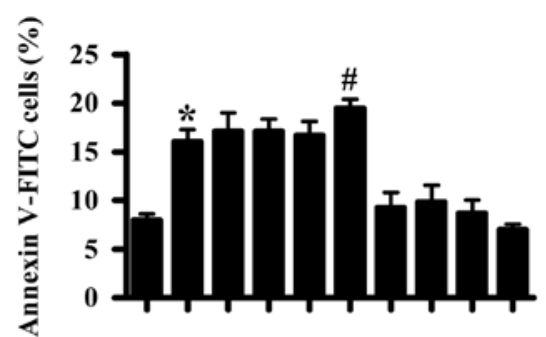

C

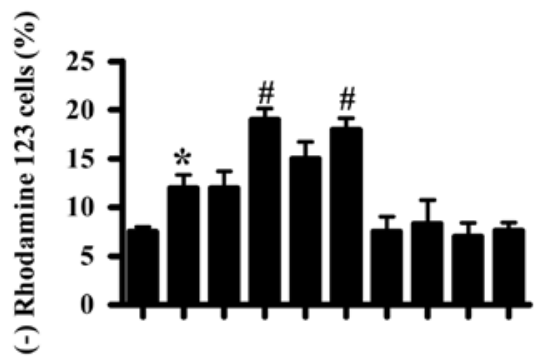

MG132 $10 \mu \mathrm{M}:-+++++-\ldots$

Z-VAD : - - + - - + + - -

Z-DEVD : - - - + - - + - -

Z-IETD : - - $-c_{-}+-c_{-}+$

Z-LEHD : - - - - - + - - - +

Figure 3. Effects of caspase inhibitors on cell growth, cell death and MMP $\left(\Delta \Psi_{\mathrm{m}}\right)$ in MG132-treated HPF cells. Exponentially growing cells were treated with $10 \mu \mathrm{M}$ MG132 for $24 \mathrm{~h}$ following a 1-h pre-incubation with $15 \mu \mathrm{M}$ of a given caspase inhibitor. (A) The graph shows cell growth changes in HPF cells as assessed by MTT assays. (B and C) Annexin V-FITC cells and MMP $\left(\Delta \Psi_{\mathrm{m}}\right)$ loss were measured with a FACStar flow cytometer. Graphs show the percent of Annexin V-positive staining cells (B) and rhodamine 123-negative [MMP $\left(\Delta \Psi_{\mathrm{m}}\right)$ loss] cells $(\mathrm{C}) .{ }^{*} \mathrm{p}<0.05$ compared with the control group. ${ }^{\#} \mathrm{p}<0.05$ compared with cells treated with MG132 only.

MG132 as a suitable dose was used to differentiate the levels of cell growth inhibition and death in the presence or absence of each caspase inhibitor [pan-caspase inhibitor (Z-VAD)], caspase-3 inhibitor (Z-DEVD), caspase- 8 inhibitor (Z-IETD), or caspase-9 inhibitor (Z-LEHD). A concentration of $15 \mu \mathrm{M}$ was used as an optimal dose of each caspase inhibitor. All of the caspase inhibitors enhanced growth inhibition in MG132-treated HPF cells (Fig. 3A). In relation to cell death, caspase-9 inhibitor among other inhibitors enhanced increased Annexin V-positive cell numbers in MG132-treated HPF cells (Fig. 3B). Moreover, caspase-3, -8 and -9 inhibitors intensified $\operatorname{MMP}\left(\Delta \Psi_{\mathrm{m}}\right)$ loss in these cells (Fig. 3C).

Effects of MG132 and/or caspase inhibitors on ROS and GSH levels in HPF cells. ROS and GSH levels in HPF cells treated with MG132 and/or each caspase inhibitor were assessed at $24 \mathrm{~h}$. As shown in Fig. 4A, the intracellular ROS level (as determined by DCF) was significantly increased in
A

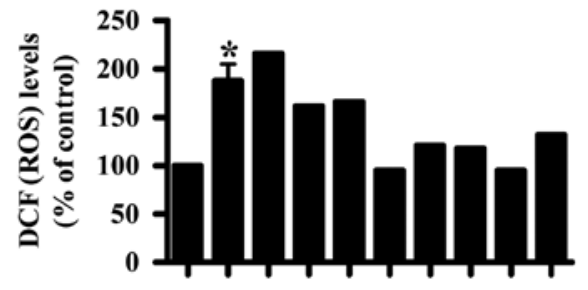

B
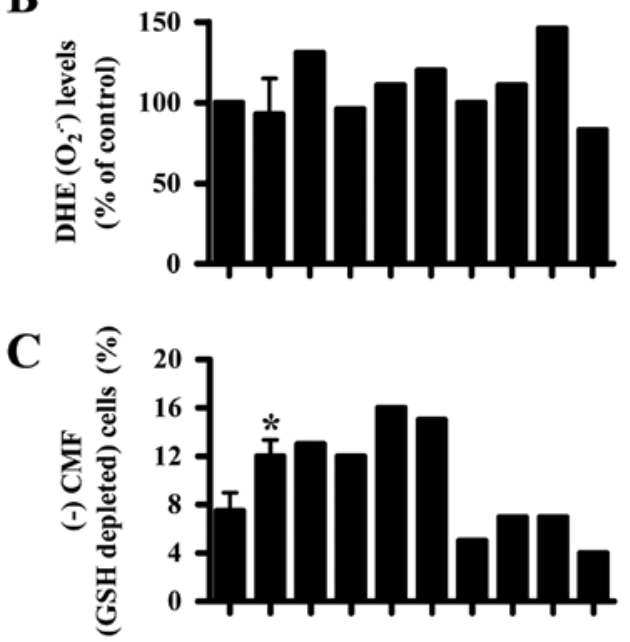

MG132 $10 \mu \mathrm{M}:-+++++---$

Z-VAD : - - + - - - + - -

Z-DEVD : - - $-++-\quad-++-$

Z-IETD : - $-c_{-}+-{ }_{-}+$

Z-LEHD : - $-\quad-\quad-+\quad-\quad-+$

Figure 4. Effects of caspase inhibitors on ROS and GSH levels in MG132treated HPF cells. Exponentially growing cells were treated with $10 \mu \mathrm{M}$ MG132 for $24 \mathrm{~h}$ following a 1-h pre-incubation with $15 \mu \mathrm{M}$ of a given caspase inhibitor. ROS and GSH levels were measured with a FACStar flow cytometer. (A and B) Graphs indicate ROS (as determined by DCF) levels (\%) (A) and DHE $\left(\mathrm{O}_{2}^{\circ}\right)$ levels (\%) compared with control cells (B). (C) Graph shows the percent of (-) CMF (GSH-depleted) cells. ${ }^{*} \mathrm{p}<0.05$ compared with the control group.

MG132-treated HPF cells. While Z-VAD slightly enhanced ROS levels in MG132-treated cells, other caspase inhibitors, especially caspase-9 inhibitor decreased the level in these cells (Fig. 4A). Red fluorescence derived from DHE, which reflected the $\mathrm{O}_{2}{ }^{-}$accumulation, was not significantly changed in MG132-treated HPF cells (Fig. 4B). Z-VAD and caspase-9 inhibitor seemed to increase $\mathrm{O}_{2}{ }^{-}$level in MG132-treated HPF cells. Caspase- 8 inhibitor alone increased $\mathrm{O}_{2}{ }^{--}$level in control cells (Fig. 4B). In relation to GSH levels in HPF cells, MG132 increased GSH-depleted cell numbers in HPF cells compared with those of the control cells and caspase- 8 and -9 inhibitors relatively increased GSH-depleted cell numbers in MG132treated HPF cells (Fig. 4C).

Effects of apoptosis-related siRNAs on apoptosis and ROS levels in MG132-treated HPF cells. Furthermore, it was determined whether apoptosis-related siRNAs changed cell death and ROS levels in MG132-treated HPF cells. As shown in Fig. 5A, $30 \mu \mathrm{M}$ MG132 increased the proportion of Annexin V-stained cells about $15 \%$ compared with that in control siRNA treated HPF cells without MG132. Treatment with $10 \mu \mathrm{M}$ MG132 did 
A
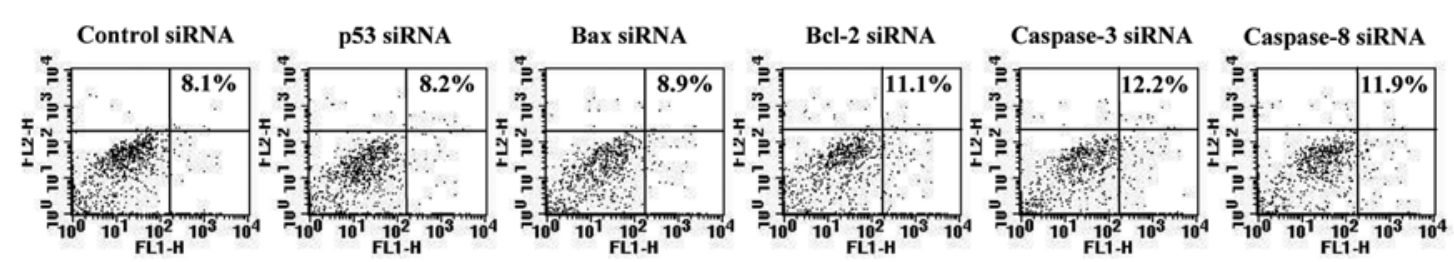

$\underline{\operatorname{MG132}(\mu \mathrm{M})}$

0
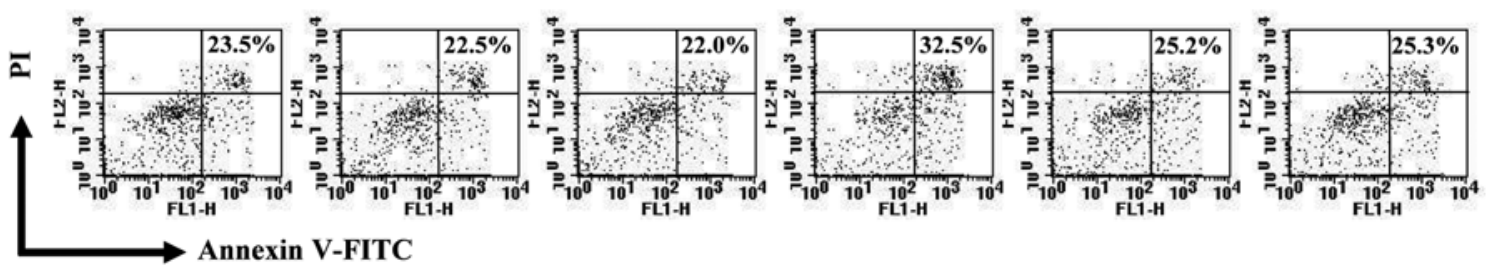

30

B

B

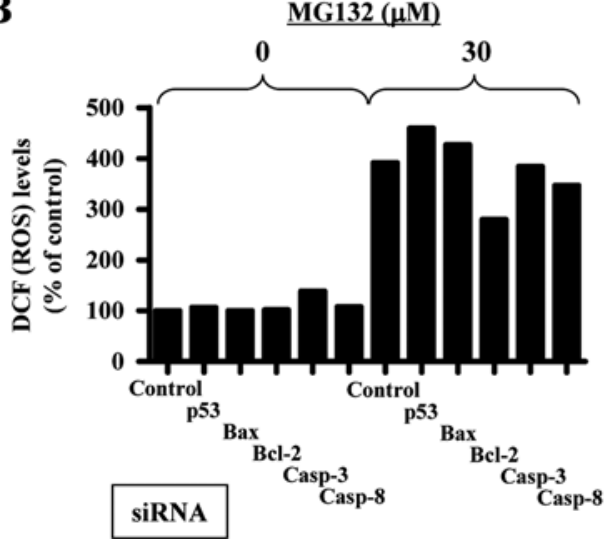

C

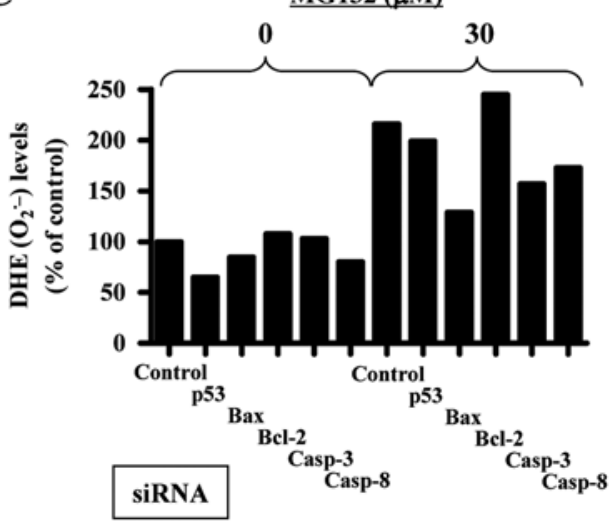

Figure 5. Effects of apoptosis-related siRNAs on apoptosis and ROS levels in MG132-treated HPF cells. HPF cells ( 30-40\% confluence) were transfected with either non-target control siRNA or each apoptosis-related siRNA. One day later, cells were treated with $30 \mu \mathrm{M}$ MG132 for additional $24 \mathrm{~h}$. (A) Annexin V-FITC and PI cells were measured with a FACStar flow cytometer. The number (\%) in each figure indicates Annexin V-FITC positive cells regard-

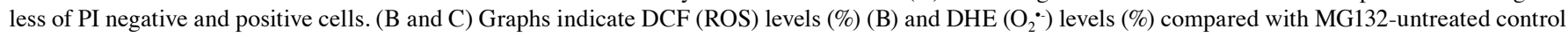
siRNA cells $(\mathrm{C})$.

not clearly increase Annexin V-stained cell number in this system (data not shown). Probably, Lipofectamine 2000 in the medium attenuated the biological activity of MG132. While p53 and Bax siRNAs did not affect Annexin V-stained cell number in MG132-treated HPF cells, Bcl-2 siRNA definitely increased the number in these cells (Fig. 5A). Caspase-3 and -8 siRNAs also slightly increased Annexin V-stained cell number in MG132-treated HPF cells (Fig. 5A). In relation to ROS levels, p53 and Bax siRNAs slightly increased ROS (DCF) level in MG132-treated cells whereas Bcl-2 and caspase- 8 siRNAs relatively decreased the level in these cells (Fig. 5B). Caspase-3 siRNA alone slightly increased ROS level in HPF control cells (Fig. 5B). In view of $\mathrm{O}_{2}{ }^{--}$level, p53, Bax and caspase-8 siRNAs decreased $\mathrm{O}_{2}{ }^{-}$level in HPF control cells (Fig. 5C). In this experimental condition, treatment with $30 \mu \mathrm{M}$ MG132 clearly increased $\mathrm{O}_{2}{ }^{-}$level in HPF cells (Fig. 5C). Bax, caspase-3 and -8 siRNAs attenuated the increased $\mathrm{O}_{2}{ }^{--}$level in MG132-treated HPF cells whereas Bcl-2 siRNA relatively increased the level (Fig. 5C).

\section{Discussion}

In the present study, we focused on investigating the molecular mechanisms of MG132 in HPF cells in relation to cell growth inhibition and death. MG132 inhibited the growth of HPF cells in a dose-dependent manner. In addition, MG132 dosedependently induced cell death in HPF cells. Furthermore, MG132 blocked the activity of proteasome in HPF cells. Consequently, this inhibition seemed to influence the growth inhibition and death of HPF cells. Based on an MTT assay, an $\mathrm{IC}_{50}$ of MG132 in HPF cells was approximately $20 \mu \mathrm{M}$. Our previous reports demonstrated that the doses of $\mathrm{IC}_{50}$ of MG132 in A549 and Calu-6 lung cancer cells were approximately 20 and $5 \mu \mathrm{M}$, respectively $(18,19)$. Therefore, these results did not strongly support the assumption that the susceptibility of HPF cells to MG132 is lower than that of lung cancer cells. Thus, the susceptibility of MG132 seems to depend on the cell type. Our DNA flow cytometric analysis demonstrated that $10 \mu \mathrm{M}$ MG132 induced S and G2-M phase arrest of the cell cycle in HPF cells. Since $10 \mu \mathrm{M}$ MG132 inhibited the growth of HPF cells approximately $40 \%$ but this dose induced cell death at most 6-8\% compared with that of control cells. This result implies that S and G2-M phase arrest by MG132 is a pathway to suppress the growth of HPF cells. According to previous reports, $0.5 \mu \mathrm{M}$ MG132 induced a $\mathrm{G} 2 / \mathrm{M}$ phase arrest in Calu-6 cells and 1-30 $\mu \mathrm{M}$ MG132 induced an S phase arrest in these cells (19). MG132 induced a G1 phase arrest of the cell cycle in A549 cells (18). Thus, the deregulation of the 
ubiquitin-proteasomal system by MG132 can differently affect cell cycle distribution depending on incubation dose and cell type in lung cells.

To gain insight into the molecular mechanism involved in MG132-mediated HPF cell death, sub-G1 cells, Annexin V staining and MMP $\left(\Delta \Psi_{\mathrm{m}}\right)$ were assessed in HPF cells. MG132 clearly induced HPF cell death which was accompanied by $\operatorname{MMP}\left(\Delta \Psi_{\mathrm{m}}\right)$ loss. In addition, MG132 increased the activities of caspase-3 and -8 in HPF cells. Thus, MG132 seemed to induce apoptosis in HPF cells. However, none of the tested caspase inhibitors prevented HPF cell death by MG132. Instead, caspase-9 inhibitor (Z-LEHD) increased Annexin V-positive cell numbers in MG132-treated HPF cells. In addition, all of the tested caspase inhibitors enhanced cell growth inhibition by MG132, and caspase-3 and -9 inhibitors significantly increased $\operatorname{MMP}\left(\Delta \Psi_{\mathrm{m}}\right)$ loss. Furthermore, caspase-3 and -8 siRNAs slightly increased Annexin V-positive cell number in MG132treated HPF cells. These data imply that MG132-induced HPF cell death occurred in a caspase-independent manner. The slight enhancement of cell death by caspase inhibitors or siRNAs in MG132-treated HPF cells probably resulted from increased necrotic cell death following the blockade of the apoptotic pathway by these agents. In relation to Calu- 6 cell death by MG132 (19), Z-VAD (pan-caspase inhibitor) significantly rescues Calu- 6 cells from MG132 insults. Therefore, the mechanism of cell death by MG132 can be different in lung cancer and normal lung cells. In addition, when p53, Bax and Bcl-2 siRNAs were administered in HPF cells treated with MG132, p53 and Bax siRNAs did not affect Annexin V-stained cell number in these cells but Bcl-2 siRNA clearly increased the number. These data imply that Bcl-2 protein, but not p53 and Bax proteins, was tightly involved in MG132-induced HPF cell death.

Proteasome inhibitors including MG132 can induce apoptotic cell death through formation of ROS (8-10). According to our results, ROS level (as determined by DCF) was significantly increased in HPF cells treated with MG132. Treatment with $10 \mu \mathrm{M}$ MG132 did not significantly affect $\mathrm{O}_{2}{ }^{-*}$ level but $30 \mu \mathrm{M}$ MG132 clearly increased $\mathrm{O}_{2}^{--}$level in control siRNAadministered cells. However, each caspase inhibitor affects differently ROS levels including $\mathrm{O}_{2}^{--}$regardless of cell growth inhibition and cell death levels. Especially, caspase-9 inhibitor showing a strong decreasing effect on ROS (DCF) level in MG132-treated cells enhanced cell death and MMP $\left(\Delta \Psi_{\mathrm{m}}\right)$ loss in these cells. In addition, Z-VAD increased $\mathrm{O}_{2}^{-}$level in MG132-treated HPF cells regardless of cell death. Caspase- 8 inhibitor alone increased $\mathrm{O}_{2}{ }^{--}$level in HPF control cells without the induction of cell death. In relation to siRNA-administered HPF cells, Bcl-2 siRNA showing an enhancement in MG132induced HPF cell death decreased the ROS (DCF) level. Bax, caspase-3 and -8 siRNAs clearly reduced $\mathrm{O}_{2}{ }^{--}$level in MG132treated cells regardless of cell death. Therefore, the ROS level changes in HPF cells treated with MG132 and/or each caspase inhibitor or apoptosis-related siRNA need to be further clarified in view of cell death. The redox status of cellular GSH is a crucial regulatory element in protein ubiquitination system (28). GSH depletion due to proteasome inhibitors can lead to cell death $(10,11)$. Likewise, MG132 treatment increased the number of GSH-depleted cells in the HPF cells. In addition, caspase- 8 and -9 inhibitors increased the number of GSH-depleted cells.
This result seemed to correlate with the observation that these inhibitors intensified cell growth inhibition or cell death in MG132-treated HPF cells.

In conclusion, MG132 induced growth inhibition and death in HPF cells in a caspase-independent manner. The growth inhibition and death of HPF cells by MG132 and/or each caspase inhibitor or apoptosis-related siRNA seemed to be related to the changes in GSH levels rather than ROS levels. Our present data provide useful information to understand the toxicological and molecular effect of MG132 on normal lung cells.

\section{Acknowledgements}

This study was supported by Basic Science Research Program through the National Research Foundation of Korea (NRF) funded by the Ministry of Education, Science and Technology (2010-0007059).

\section{References}

1. Orlowski RZ: The role of the ubiquitin-proteasome pathway in apoptosis. Cell Death Differ 6: 303-313, 1999.

2. Voges D, Zwickl P and Baumeister W: The 26S proteasome: a molecular machine designed for controlled proteolysis. Annu Rev Biochem 68: 1015-1068, 1999.

3. Orlowski M and Wilk S: Catalytic activities of the $20 \mathrm{~S}$ proteasome, a multicatalytic proteinase complex. Arch Biochem Biophys 383: 1-16, 2000.

4. Adams J: The proteasome: a suitable antineoplastic target. Nat Rev Cancer 4: 349-360, 2004.

5. Drexler HC: Activation of the cell death program by inhibition of proteasome function. Proc Natl Acad Sci USA 94: 855-860, 1997.

6. Shah SA, Potter MW and Callery MP: Ubiquitin proteasome pathway: implications and advances in cancer therapy. Surg Oncol 10: 43-52, 2001

7. Lee DH and Goldberg AL: Proteasome inhibitors: valuable new tools for cell biologists. Trends Cell Biol 8: 397-403, 1998.

8. Wu HM, Chi KH and Lin WW: Proteasome inhibitors stimulate activator protein-1 pathway via reactive oxygen species production. FEBS Lett 526: 101-105, 2002.

9. Perez-Galan P, Roue G, Villamor N, Montserrat E, Campo E and Colomer D: The proteasome inhibitor bortezomib induces apoptosis in mantle-cell lymphoma through generation of ROS and Noxa activation independent of p53 status. Blood 107: 257-264, 2006.

10. Ling YH, Liebes L, Zou Y and Perez-Soler R: Reactive oxygen species generation and mitochondrial dysfunction in the apoptotic response to Bortezomib, a novel proteasome inhibitor, in human H460 non-small cell lung cancer cells. J Biol Chem 278: 33714-33723, 2003.

11. Qiu JH, Asai A, Chi S, Saito N, Hamada H and Kirino T: Proteasome inhibitors induce cytochrome $\mathrm{C}$ caspase-3-like protease-mediated apoptosis in cultured cortical neurons. J Neurosci 20: 259-265, 2000.

12. Chen TJ, Jeng JY, Lin CW, Wu CY and Chen YC: Quercetin inhibition of ROS-dependent and -independent apoptosis in rat glioma C6 cells. Toxicology 223: 113-126, 2006.

13. Dasmahapatra G, Rahmani M, Dent P and Grant S: The tyrphostin adaphostin interacts synergistically with proteasome inhibitors to induce apoptosis in human leukemia cells through a reactive oxygen species (ROS)-dependent mechanism. Blood 107: 232-240, 2006.

14. Wallach-Dayan SB, Izbicki G, Cohen PY, Gerstl-Golan R, Fine A and Breuer R: Bleomycin initiates apoptosis of lung epithelial cells by ROS but not by Fas/FasL pathway. Am J Physiol Lung Cell Mol Physiol 290: L790-L796, 2006.

15. Petty RD, Nicolson MC, Kerr KM, Collie-Duguid E and Murray GI: Gene expression profiling in non-small cell lung cancer: from molecular mechanisms to clinical application. Clin Cancer Res 10: 3237-3248, 2004. 
16. Mortenson MM, Schlieman MG, Virudachalam S and Bold RJ: Effects of the proteasome inhibitor bortezomib alone and in combination with chemotherapy in the A549 non-small-cell lung cancer cell line. Cancer Chemother Pharmacol 54: 343-353, 2004.

17. Ling YH, Liebes L, Jiang JD, Holland JF, Elliott PJ, Adams J, Muggia FM and Perez-Soler R: Mechanisms of proteasome inhibitor PS-341-induced G(2)-M-phase arrest and apoptosis in human non-small cell lung cancer cell lines. Clin Cancer Res 9: $1145-1154,2003$.

18. Han YH and Park WH: MG132 as a proteasome inhibitor induces cell growth inhibition and cell death in A549 lung cancer cells via influencing reactive oxygen species and GSH level. Hum Exp Toxicol 29: 607-614, 2010.

19. Han YH and Park WH: MG132, a proteasome inhibitor decreased the growth of Calu- 6 lung cancer cells via apoptosis and GSH depletion. Toxicol In Vitro 24: 1237-1242, 2010.

20. Han YH, Kim SZ, Kim SH and Park WH: Pyrogallol inhibits the growth of lung cancer Calu-6 cells via caspase-dependent apoptosis. Chem Biol Interact 177: 107-114, 2009.

21. Park WH, Seol JG, Kim ES, Hyun JM, Jung CW, Lee CC, Kim BK and Lee YY: Arsenic trioxide-mediated growth inhibition in MC/CAR myeloma cells via cell cycle arrest in association with induction of cyclin-dependent kinase inhibitor, p21, and apoptosis. Cancer Res 60: 3065-3071, 2000.
22. Han YH, Kim SZ, Kim SH and Park WH: Arsenic trioxide inhibits growth of As4.1 juxtaglomerular cells via cell cycle arrest and caspase-independent apoptosis. Am J Physiol Renal Physiol 293: F511-F520, 2007.

23. Han YH, Kim SZ, Kim SH and Park WH: Apoptosis in pyrogallol-treated Calu- 6 cells is correlated with the changes of intracellular GSH levels rather than ROS levels. Lung Cancer 59: 301-314, 2008.

24. Han YH, Kim SH, Kim SZ and Park WH: Caspase inhibitor decreases apoptosis in pyrogallol-treated lung cancer Calu-6 cells via the prevention of GSH depletion. Int J Oncol 33: 1099-1105, 2008.

25. Elbashir SM, Harborth J, Lendeckel W, Yalcin A, Weber K and Tuschl T: Duplexes of 21-nucleotide RNAs mediate RNA interference in cultured mammalian cells. Nature 411: 494-498, 2001.

26. Porter AG and Janicke RU: Emerging roles of caspase-3 in apoptosis. Cell Death Differ 6: 99-104, 1999.

27. Ashkenazi A and Dixit VM: Death receptors: signaling and modulation. Science 281: 1305-1308, 1998.

28. Jahngen-Hodge J, Obin MS, Gong X, Shang F, Nowell TR Jr, Gong J, Abasi H, Blumberg J and Taylor A: Regulation of ubiquitinconjugating enzymes by glutathione following oxidative stress. J Biol Chem 272: 28218-28226, 1997. 